\title{
A concepção de corpo dos estudantes de graduação em Educação Física
}

\author{
Rafael Assad Aranda ${ }^{1}$ \\ Ana Maria Pereira ${ }^{2}$ \\ José Augusto Palma ${ }^{2}$ \\ Ângela Pereira Teixeira Victoria Palma ${ }^{2}$ \\ ${ }^{1}$ Centro de Educação Física e Esporte, Universidade Estadual de Londrina, PR, Brasil \\ ${ }^{2}$ Laboratório de Pesquisa em Educação Física (LaPEF), Centro de Educação Física \\ e Esporte, Universidade Estadual de Londrina, PR, Brasil
}

\begin{abstract}
Resumo: $O$ objetivo desta pesquisa foi identificar quais concepções de corpo/corporeidade têm os estudantes dos cursos de graduação licenciatura em Educação Física da Universidade Estadual de Londrina. Orientado sob a ótica da pesquisa qualitativa em educação, abordagem antropológica de cunho fenomenológico, realizou-se pesquisa de campo por meio de entrevista semiestruturada buscando informações e conhecimentos. A amostra foi selecionada a partir da estratificação proporcional da população que compunha as 05 turmas em conclusão dos cursos no ano de 2008, composta de 15 estudantes, sendo $10 \%$ de cada turma, nomeadamente: licenciatura generalista (CFE, 03/87) e licenciatura atual (CNE 01 02/2002). Após análise dos resultados verificou-se que a concepção de corpo/corporeidade assimilada pelos estudantes do currículo licenciatura generalista aproximou-se de corpo físico, dualista e instrumental. Os estudantes do currículo licenciatura atual estão construindo uma concepção de corpo/corporeidade sob a égide do paradigma da unidade e da totalidade, compreendendo o humano que se movimenta intencionalmente.
\end{abstract}

Palavras-chave: Educação Física. Corpo. Corporeidade.

\section{The body conception of undergraduate students in Physical Education}

\begin{abstract}
The aim of this study was to identify the body and corporeality conceptions shared by students attending a degree course in Physical Education at the State University of Londrina (UEL). By adopting a qualitative research paradigm in education as well as an anthropological approach of phenomenological nature, a field research was conducted through semi-structured interviews, which aimed at revealing information and knowledge. The sample was selected based on the proportional stratification of the population that comprised five last year's classes of the aforementioned course in the year of 2008, totalling 15 students, $10 \%$ of which corresponded to each separate class, namely: generalist bachelor's degree (CFE, 03/87) and current bachelor's degree (CNE 01 02/2002).After the analysis of the results, it was verified that the conception of body and corporeality assimilated by the students of the generalist bachelor's degree approximated to that of physical body - dualist and instrumental. The students of the current bachelor's degree are developing a conception of body and corporeality under the aegis of the paradigm of unity and totality, acknowledging that humans move intentionally.
\end{abstract}

Keywords: Physical Education. Body. Corporeality.

\section{Introdução}

O Centro de Educação Física e Esporte (CEFE) da Universidade Estadual de Londrina (UEL), especificamente, o Departamento de Estudos do Movimento Humano (EMH), em 2005, implementou um novo currículo de Educação Física: Habilitação específica em Licenciatura, pautada nas Resoluções do Conselho Nacional de Educação - CNE 01 e 02/2002.

A opção por uma habilitação específica em Licenciatura teve 0 objetivo de alcançar a qualidade na formação de professores, porque tradicionalmente, no âmbito da Educação Física, a formação inicial se consolidou numa perspectiva "generalista". Os currículos da Educação Física, em todo o país, estiveram sob o impacto da Resolução do Conselho Federal de Educação CFE no. 03/87. Essa formação capacitava o futuro profissional para atuar no mercado de trabalho no âmbito da escola e fora dessa, nomeadamente, na atividade física e saúde, no lazer e animação sociocultural, ainda, no treinamento esportivo. Grande parte da comunidade acadêmicocientífica da Educação Física questionou essa organização curricular e concluiu que esse tipo de 
ação não favorecia uma formação consistente, rigorosa, radical e profunda, devido à diversidade de intervenções/atuações no mundo do trabalho.

Na UEL, o currículo Licenciatura Generalista, teve o seu primeiro vestibular em 1992 e último em 2004, sob a égide da resolução CFE nº 03/87, tinha como objetivo a formação inicial em Educação Física, sendo a atuação no âmbito escolar (ensino infantil, fundamental e médio), na área não escolar (organizações públicas ou privadas) e ainda, nas esferas do treinamento esportivo. O perfil do concluinte da Licenciatura Generalista era de professor em educação básica; prestador de serviços e assessorias relacionados à Educação Física, avaliação e prescrição de atividades físicas, recreativas e lazer; como também, orientador e técnico esportivo. Os princípios que fundamentavam este curso, devido ao caráter generalista, estavam atrelados à explicação do movimento humano em seus aspectos biológicos, com ênfase na eficácia e na eficiência da performance esportiva, sendo a matriz curricular com significativo percentual de disciplinas da área médica.

Na UEL, o currículo Licenciatura Atual, vigente até então, implantado em 2005, regido pelas Resoluções CNE/CP 01 e 02, de 2002, tem como objetivo promover a formação de professores para a atuação no processo ensino-aprendizagem da Educação Física em todos os níveis e modalidades de ensino, bem como 0 desenvolvimento de estudos e pesquisas da área no que se refere aos processos educativos. $O$ perfil do concluinte é de educador qualificado para a ação docente nos diferentes níveis e modalidades de educação e ensino. Os princípios que fundamentam este curso, tendo em vista a habilitação específica em licenciatura, caracterizam-se por compreender o homem cultural e social sob o paradigma da complexidade e da unidade, considerando uma motricidade intencional carregada de sentido e de significado.

Então, no ano de 2008, na UEL, formaram-se as últimas turmas do currículo anterior, Curso de Educação Física Licenciatura Plena "Generalista", que ingressaram no ano de 2004, e que para o período noturno eram necessários 05 anos para a sua integralização. Também, nesse ano de 2008, se formaram as primeiras turmas do novo currículo, Curso de Educação Física, "Habilitação em Licenciatura", que ingressaram no ano de
2005. Observa-se que na UEL de 2004 a 2008 houve a materialização de 02 currículos em simultâneo (Resoluções CFE n 03/87 e CNE/CP 01 e 02, de 2002) com diferença temporal de início de 01 ano para os estudantes de Licenciatura Generalista.

Sendo assim, numa delimitação para este estudo, elaboraram-se as seguintes questões: Qual a concepção que os estudantes dos cursos de graduação em Educação Física licenciatura têm sobre corpo/corporeidade? Os Cursos de Graduação em Educação Física colaboraram na construção de uma concepção de corpo legitimado na ciência e na filosofia? Existe diferença na concepção de corpo dos estudantes que frequentaram 0 curso baseado nas Resoluções CFE 03/87 (ingressantes em 2004 e formados em 2008) e dos que frequentaram o curso baseado nas Resoluções CNE 01 e 02 /2002 (ingressantes em 2005 e formados em 2008)?

Esta pesquisa teve como objetivo identificar a concepção de corpo/corporeidade dos estudantes das últimas turmas do Curso de Educação Física Licenciatura com base na Resolução CFE 03/87, ingressantes no ano de 2004 e dos estudantes das primeiras turmas do Curso de Educação Física Habilitação em Licenciatura, com base nas Resoluções CNE 01 e 02/2002, ingressantes no ano de 2005.

Doravante, utilizaremos as expressões: Licenciatura Generalista e Licenciatura Atual, para identificar os diferentes cursos de formação inicial.

Nesta pesquisa, em sua primeira fase, realizaram-se estudos da evolução da concepção de corpo ao longo dos tempos considerando aspectos históricos e filosóficos, bem como das concepções de corpo/corporeidade que estão presentes na contemporaneidade. Na segunda fase, analisou-se a concepção de corpo assimilada pelos estudantes de graduação do curso de Educação Física da formação generalista e da formação do licenciado.

\section{Metodologia: a trajetória escolhida}

Este estudo em Educação Física foi orientado sob a ótica da pesquisa qualitativa em educação, com aproximação fenomenológica. A pesquisa qualitativa pode utilizar-se da descrição dos fenômenos como recurso básico e inicial, porque permite conhecer como os indivíduos ou os 
grupos representam as palavras para si mesmos, como compõem os discursos reais, como revelam e ocultam neles o que estão pensando ou dizendo, como deixam um conjunto de traços verbais daquilo que pensam (Martins, 1989).

A descrição, interpretação e compreensão de um fenômeno constitui um exercício fenomenológico, que propõe um retorno à totalidade do mundo vivido, recupera aquilo que ficou esquecido e questiona os fundamentos dos fenômenos que estão estabelecidos como certeza. É uma atitude de abertura do ser humano para compreender o que se mostra, ou seja, busca revelar a essência do fenômeno (MASINI, 1989).

Primeiramente, na lógica da hermenêutica, realizaram-se estudos rigorosos e de conjunto, para compreender, interpretar as mensagens e os sinais que envolvem 0 texto e o contexto do objeto de estudo em questão, a concepção de corpo/corporeidade (RICOEUR, 1978).

Em seguida, fez-se necessário uma pesquisa de campo, por meio de entrevista semiestruturada, na qual foram feitas as questões pertinentes ao tema investigado, questões essas idealizadas a priori, sendo estas: 1 - O que é, para você, corpo? 2- E corporeidade? 3- Com que corpo/corporeidade a atual Educação Física está preocupada?

Realizaram-se 02 entrevistas-piloto, uma com um estudante da Licenciatura Generalista e outra com um estudante da Licenciatura Atual, escolhidos aleatoriamente, para verificar a compreensão dos estudantes sobre as perguntas pré-elaboradas. Os dados das entrevistas-piloto não foram utilizados na análise dos resultados da presente pesquisa.

A amostra foi selecionada a partir da estratificação proporcional, segundo Lakatos e Marconi (2002), cuja técnica consiste em escolher, de cada unidade de amostragem, uma amostra aleatória proporcional à extensão da unidade de amostragem. Ela foi composta no total por 15 estudantes, sendo $10 \%$ de cada turma, ou seja, 09 estudantes das três últimas turmas (03 do noturno), do Curso de Educação Física, Licenciatura Generalista. E ainda, 06 estudantes das duas primeiras turmas (01 do matutino e 01 do noturno) do Curso de Educação Física, Habilitação em Licenciatura Atual.
Os dizeres dos estudantes entrevistados foram gravados $e$, posteriormente, transcritos na íntegra. Tendo em vista que a pesquisa é qualitativa com aproximação fenomenológica utilizou-se do recurso básico que é a descrição, traduzida num conjunto de manifestações verbais dos pensamentos daqueles que dispuseram a falar sobre o tema em foco. Na medida em que foi realizada a leitura cuidadosa de cada descrição apreenderam-se as "unidades de significado", que indicam as ideias dos discursos dos sujeitos. No todo da descrição nada se apresentou isolado. Desse modo, fez-se necessário realizar um movimento de redução, que consistiu em uma síntese daquilo que foi revelado pelos sujeitos, agrupando por temas, buscando a compreensão da essência da estrutura do fenômeno. A partir de então, passou-se a uma profunda reflexão sobre a estrutura do fenômeno obtendo generalidades indicadas pelas convergências dos discursos reveladas pelos sujeitos.

Em respeito aos preceitos éticos de pesquisa que envolve seres humanos, os sujeitos entrevistados assinaram um termo de consentimento, concordando em participar da pesquisa, aprovado pelo Comitê de Ética em Pesquisa, envolvendo Seres Humanos, da Universidade Estadual de Londrina (CEP-UEL) sob parecer no 167/10 e Comitê Nacional de Ética em Pesquisa (CONEP), Folha de Rosto no 359674.

\section{Concepção de corpo: evolução e nuances}

\section{O dualismo instrumental da Antiguidade ao Renascimento}

Atualmente o corpo está em evidência. A pósmodernidade sugere tipos de corpos que sejam aceitos pela sociedade e não se admite nenhuma imperfeição, não pode ser gordo, feio, velho, ou seja, há um padrão imposto e pré-estabelecido. A problemática em questão é que a maioria das pessoas não se ajusta ao modelo globalizado que está em moda e que é fortemente divulgado pela mídia. Para compreender o corpo humano da contemporaneidade foi necessário estudar as concepções de corpo ao longo da história, desde a Pré-História até a Modernidade. Pesquisar a evolução do conceito de corpo sob a ótica histórica e filosófica revelou de modo concreto as marcas em seu modo de ser/estar em diferentes momentos que a sociedade viveu e vive. 
Nos primórdios dos tempos o homem foi uno em sua existência concreta, porque a sua experiência no mundo era enfrentamento vivo. $\mathrm{O}$ primitivo estava unido consigo mesmo, com seu povo, com a terra, com a natureza, com o cosmo. O sensível e o inteligível estavam conectados numa concepção de humano uno e inteiro. $O$ primitivo não distinguia o pensamento do corpo, da natureza ou da terra (GUSDORF,1980; GONCALVES, 1994).

$\mathrm{Na}$ Antiguidade, tem-se a mais antiga e difusa concepção de corpo. Platão em "Fédon, 82 d" afirma: "que o corpo constituía para a alma uma espécie de prisão" (PLATÃO, 1979, p. 88). Este filósofo dividiu a realidade humana em duas partes, sendo estas o mundo inteligível (alma superior) e o mundo sensível (corpo inferior). $O$ corpo matéria perturba a alma racional na busca do conhecimento verdadeiro, pois, o corpo por meio dos sentidos reproduz apenas a cópia das ideias. Assim, o corpo útil, cumpre função de instrumento, porque ele serve para a alma habitálo. Aristóteles também revelou a noção de corpo com características instrumentais, mas entendeu que no corpo existe o "princípio do movimento" (PEREIRA, 2006). O pensador salienta a importância do corpo biológico, considerando a saúde e a beleza do corpo como virtudes agradáveis e boas. Nota-se que sensível e inteligível não constituem dois mundos totalmente separados como em Platão, pois ele considera estes dois aspectos no processo de construção do conhecimento. Entretanto, mesmo com algum avanço na concepção de corpo em Aristóteles, a dicotomia é evidente, revelando a permanência constante da submissão do corpo em relação à alma.

A Idade Média ressignificou a concepção instrumental clássica sob a égide dos princípios cristãos e a filosofia se conecta com a teologia. Observa-se na filosofia de Santo Agostinho e São Tomás de Aquino uma hierarquia da alma sobre 0 corpo, sendo este último submisso ao divino e fonte de pecado (JANA, 1995; GALLO, 2006). A concepção dualista era evidente no mundo medieval, as dicotomias foram intensas, tais como: o bem e o mal, o sagrado e o profano. $O$ homem ficou dividido, o ser era formado de carne e espírito, sendo que de um lado se apresenta a alma; a imortal que aspira à perfeição celeste, e do outro lado, o corpo; o mortal putrescível, que deverá virar pó.
No período do Renascimento surgiu um conceito dinâmico de homem, pautado no sentido filantrópico e antropocêntrico, tentando-se assim libertar o homem da clausura da Idade Média, mas, mesmo assim, manteve-se a premissa instrumental entre corpo e alma (PEREIRA, 2006).

\section{O dualismo antropológico cartesiano da Modernidade}

A Idade Moderna, após o Renascimento, foi marcada pelas ideias filosóficas de René Descartes que separou radicalmente corpo e alma. O homem foi compreendido pela constituição de duas partes: a res cogitans e a res extensa, como duas substâncias diferentes e independentes. O homem, neste período, teve um corpo distinto e autônomo e passou a ser objeto da ciência (ANJOS, 1995; GALLO, 2006; INFORSATO, 2006). O racionalismo cartesiano, um dos pilares da modernidade, acarretou a supremacia da cabeça, lugar do cérebro, sobre os outros órgãos. O âmbito educacional assimilou essa ideologia, pois nas práticas exercidas a 'cabeça' acaba sempre como o centro do processo, em que qualquer fazer é útil e necessário subjugado pelo pensamento. A doutrina cartesiana atingiu todas as áreas do conhecimento, bem como todas as práticas sociais dela decorrentes.

$\mathrm{Na}$ atualidade concebe-se a noção de corpo de variadas óticas, de diferentes abordagens e de concepções teóricas. Na contemporaneidade não estaria o ser humano se instrumentalizando por meio do seu próprio corpo? Agora a noção instrumental aparece ressignificada e compactuada com os estereótipos da sociedade moderna, apresentando o corpo como matéria moldável de acordo com o poder, as normas, os ditames presentes no âmbito sociocultural.

\section{Os diferentes corpos dos tempos contemporâneos}

Observam-se na contemporaneidade as concepções de corpo conectadas à identidade do sujeito. A concepção de corpo não está ligada a uma consciência, ou a um arcabouço de grandes ideários como já foi outrora (GHIRALDELLI JUNIOR, 2007). O corpo corre o risco de se conectar às noções de instrumentalidade a serviço da tecnologia e da ciência, do trabalho, da 
ordem e do progresso, da saúde, da estética, da moda, entre outros. Vejamos a seguir as várias manifestações em que o corpo se revela.

Ainda hoje se depara com as concepções de corpo que Assmann (1995) elucidou: o corpo 'jardim fechado', que está relacionado aos dogmas religiosos que impõem ao corpo 0 significado de morada, de templo sagrado e, ao mesmo tempo, corpo que não pode ceder aos desejos do homem. Esta concepção remete à noção de instrumentalidade presente na Idade Média, quando se vivia em função do espiritual; $O$ corpo 'aberto e devassável', ligado ao corpo máquina de Descartes, corpo objeto que pode ser 'manuseado', invadido e explorado, o corpo da ciência, o anatômico; O 'corpo ajustável ao que se precisa', é considerado o corpo moderno, pois é maleável, elástico e plástico, ocupa diversas funções ao mesmo tempo, adaptando-se a todas; O 'corpo político', aquele que se organiza por meio de princípios de organização da sociedade a fim de alcançar metas e objetivos comuns; corpos esvoaçantes, aqueles produzidos pela mídia, seguem o modismo; 'Corpo desafiador', é o corpo bio-psico-energético das ciências denominadas obtusas, constitui-se pelo desafio do conhecimento que se encontra na pele e além dela, sensorial e extra-sensorial; E 'corpos imagéticos', cuja realidade simulada faz com que tudo vire abstrato e se crie imagens gerando uma indiferença emocional.

Moreira (1995) faz uso de algumas concepções de Assmann e de Foucault. Resgata o 'corpo dócil', objeto e alvo de poder, controlado pela disciplina e cujas ações são delimitadas pelo espaço, tempo e movimento. Corpo dócil é sinônimo de corpo útil e disciplinado, que responde a um padrão exigido para a manutenção do poder. Outra concepção é o 'corpo asceta-indiferente', cujas relações corporais ocorrem por uma indiferença emocional e nos levam a olhar demasiadamente para fora (para a tecnologia e para os objetos), não conseguindo identificar as necessidades $e$ desejos do próprio corpo e/ou dos corpos que estão ao lado. E, também, há o 'corpo indiferente', corpo que um dia foi celebridade, mas se tornou anônimo e desprezado.

A Revolução Industrial produziu o 'corpo operário'. Anjos (1995) explica que o corpo é o primeiro e principal meio de produção (individual e social), pois a maioria da força de trabalho está ligada à capacidade corporal. Assim, o corpo é veículo de produção, tem valor de troca, e é também capital. Segundo Johnson (1990), as ideologias presentes na sociedade exerceram influências sobre a concepção de corpo, determinando um corpo útil para alcançar os objetivos sociais dominantes de ordem e progresso.

Andrieu (2004), em seus estudos, apresenta uma concepção de corpo como um sinal de identidade que não passa de uma modalidade da aparência e da superfície social. Desse modo, o corpo, hoje, é 'auto-móvel' na cidade, 'corpo movente', reflexo de uma mobilidade interior, modificado pelos deslocamentos no espaçotempo urbano e conforme a ideologia predominante.

A tecnologia do século XXI fez surgir o 'corpo hipermusculoso'. Houve uma mudança das representações culturais do corpo, pois a robustez muscular já "foi tratada como aberração humana potencialmente perigosa à constituição física geral" (FRAGA, 2001, p. 69), e, agora pode ser vista como uma dádiva frente à fraqueza orgânica. Adota-se a ideia do body-building de construção hipertrofiada do corpo. Nessa lógica anatômica, ficaram comuns os anabolizantes, com o sentido de facilidade, efemeridade, rapidez e valorização dos resultados obtidos: ótimo desempenho em tempo reduzido.

Sérgio (2005) discute o 'corpo cyborg', fruto do cruzamento homem e máquina, que vem sendo modelado, reforçado com próteses, mesclando o orgânico e o inorgânico, cuja identidade que se estabelece não é o eu e nem o outro, mas sim o status adquirido via tecnologia e medicina. Essa concepção de corpo também vai ao encontro da noção de corpo encontrada nas reflexões de Sant'anna (2001), em que o homem se sujeita à tecnologia científica e aos modismos, tornando-se objeto de consumo, adaptando-se aos implantes e a inserção de outros elementos materiais.

Ao realizar reflexões sobre o corpo, sob a perspectiva histórica e filosófica, percebeu-se que existem símbolos e signos da cultura, traduzido em diferentes concepções que habitam ou incorporam o cotidiano do ser humano. Para além dos instrumentalismos e do corpo-
objeto

Frente às instrumentalizações do corpo-carneorgânico no mundo contemporâneo, as antigas 
cisões entre corpo/sensível e alma/inteligível parecem não ter mais tanta relevância, porque a noção de corpo se valorizou e o ser humano se libertou dos controles morais do passado. Entretanto, há que refletir que o humano não tem conseguido escapar do fascínio da imagem do corpo veiculada pela mídia global nas suas mais variadas vertentes.

Na ânsia de emancipação, o corpo foi utilizado como instrumento para exercício de liberdade. Ora, faço do meu corpo o que eu quero e desejo! A questão que se põe agora é: será que, na vontade de se libertar, o corpo não acabou sendo explorado e violentado?

A superação do fragmento entre sensível e inteligível efetivaram-se nas concepções de corpo sob 0 viés da filosofia, demonstrando perspectivas em compreender o humano e suas relações com o mundo por meio do corpo uno. $A$ fenomenologia pontiana se contrapôs ao dualismo cartesiano, com a defesa de que o pensamento se dá pela existência do ser-no-mundo, em que o corpo ocupa lugar especial na existência humana (MERLEAU-PONTY, 1994).

Todavia, a esperança, mesmo que carregada de romantismo, é que o corpo abandone a noção de objeto e de instrumentalidade, seja da alma ou da indústria tecnológica midiática, e se apresente como corporeidade em ato.

Os humanos se distinguem entre si devido a sua construção social e cultural. Todo homem é portador de especificidades/identidades e esta identificação ocorre via corporeidade. Filetti e Silva (2008) afirmam que o corpo é a representação universal de homem social e constitui-se juntamente com os contextos históricos, políticos e culturais. Então, o 'corpo é produto e produtor de cultura'. Diferente do corpo que é moldado pela cultura dominante, ou instrumento da mesma, tem-se o pressuposto de que os humanos, com seus corpos, podem fazer parte e transformar a realidade. Corpos vivos, corpos práxicos, em tempo e espaço diferenciados, podem experimentar/aceitar possibilidades diferentes, superar preconceitos, gordura, velhice e feiura.

Para superar a noção de corpo objeto, Moreira (1995) defende a concepção de 'corpo presentepressente', concepção global do homem, que se relaciona com outros corpos e com o mundo, revelando ao mesmo tempo individualidade e cultura por meio das relações sociais.

Em oposição às tecnologias emergentes e o poder estabelecidos por elas, Gallo (2006) propõe a concepção de 'corpo ativo' como forma de resistência ao hiper-consumo, ao efêmero, à imposição da estética, ao narcisismo exagerado, ao controle generalizado e, ainda, à noção de corpo objeto da razão.

Silva (1999), em seus trabalhos revela o 'corpo fractal', aquele que se atém à parte e nunca abandona o todo, porque a perspectiva fractal do conceito de Mandelbrot está sob o paradigma da complexidade, em que o corpo é entendido a partir de um lugar que reconheça o pormenor, mas que também identifique e considere o todo no todo, sem distinção e separação.

A partir dos pressupostos de Edgar Morin, Campanholi (2008) sugeriu o termo unidual para conceber o homem a partir da complexidade. A concepção 'unidual de homem' considera que o ser humano é composto de partes, mas que a simples soma dessas partes não forma o todo, o qual se configura por meio das inter-relações das partes. A compreensão complexa de corpo busca a unidade, sem negar a dualidade, que é diferente de dualismo.

A concepção de corpo, na ótica da unidade/complexidade, pode libertar o homem das limitações que $o$ corpo dualista ou instrumental promoveu e que o tornou submisso, seja por meio da razão, das ideologias ou modelos dominantes e dos dogmas. Há que preservar o humano e romper com a alienação e a auto alienação. Sabe-se da dificuldade de apreender/conhecer tudo sobre a corporeidade humana, entretanto não se desiste do projeto de emancipação humana, da vida em plenitude, da ação no mundo com intencionalidade e responsabilidade, com autonomia e ética promovendo a evolução individual e, sobretudo, da coletividade.

\section{Análises e discussões do fenômeno corpo/corporeidade}

Nesta parte do trabalho, há uma interação entre o conhecimento, decorrente de uma radical e rigorosa revisão de literatura, e as descrições obtidas a partir das entrevistas semiestruturadas. 
Os sujeitos foram identificados por siglas e números: Os estudantes do currículo antigo estão identificados pela sigla $\mathrm{E}$ (Estudante), seguida do seu respectivo número e da identificação do seu curso LG (Licenciatura Generalista). Os estudantes do currículo atual estão identificados pela sigla E (Estudante), seguida do seu respectivo número e da identificação do seu curso LA (Licenciatura Atual).

Os discursos foram organizados em categorias. Elaboraram-se matrizes explicativas contendo todas as categorias, demonstradas em forma de quadros, que revelam a estrutura e a essência do fenômeno.

Quadro 1. A concepção de corpo.

\begin{tabular}{|l|c|}
\hline \multicolumn{1}{|c|}{ Categorias } & Estudantes \\
\hline $\begin{array}{l}\text { - Corpo físico (aparência; membros; estrutura } \\
\text { formada por componentes biológicos e } \\
\text { fisiológicos; união de órgãos; objeto; aspecto } \\
\text { anatômico) }\end{array}$ & E1LG, E2LG, E3LG, E4LG, E5LG, E7LG, E8LG, E9LG \\
\hline $\begin{array}{l}\text { - Corpo utilizado para se movimentar e que } \\
\text { reproduz movimentos }\end{array}$ & E1LG, E8LG, E4LA \\
\hline $\begin{array}{l}\text { - Corpo como algo relacionado à saúde (qualidade } \\
\text { de vida; o que nos dá vida) }\end{array}$ & E2LG, E7LG \\
\hline - Algo relacionado à estética e a beleza & E4LG \\
\hline - Corpo é soma das partes (fragmentos) & E4LG, E5LG, E8LG \\
\hline - Corpo é expressão & E6LG, E4LA, E5LA \\
\hline - Base para viver (vida baseada no corpo) & E7LG, E9LG, E5LA \\
\hline $\begin{array}{l}\text { - Existência do humano e o homem na sua } \\
\text { totalidade }\end{array}$ & E1LA, E2LA, E3LA, E5LA, E6LA \\
\hline
\end{tabular}

A partir das categorias extraídas da descrição, dos discursos dos sujeitos, verifica-se que a maioria dos estudantes da Licenciatura Generalista, E1LG, E2LG, E3LG, E4LG, E5LG, E7LG, E8LG, E9LG, concebe o homem como sendo um ser que tem um corpo separado da mente, às vezes sob a ótica do dualismo cartesiano, traduzido na dimensão de corpo apenas como estrutura física, como máquina. Outras vezes, como instrumento de estruturas sociais presentes na atualidade, tais como: saúde, estética, mídia e modismos decorrentes.

Os estudantes, como E1LG e E3LG, apresentam uma concepção simplista do entendimento de corpo, pois em suas falas 0 humano aparece como um conjunto de partes, nomeadamente, cabeça, tronco e membros. E3LG - [...] corpo é corpo. São membros. O estudante somente se recordou dos membros. Esse pensamento corrobora 0 paradigma cartesiano, que identifica o corpo como uma extensão do ser humano, bem como o corpo 'aberto' e devassável, de Assmann (1995), sob a égide da anatomia.

O estudante E2LG afirmou que: - [...] o corpo é mais atrelado à saúde. [...] algo que utilizo para movimentar-me... pra ver as minhas funções. $\mathrm{E}$ os E7LG e E4LG disseram que: - o corpo é algo relacionado à saúde ou à estética. A noção de corpo destes estudantes remete a uma concepção de instrumentalidade, como àqueles corpos que foram descritos por Assmann (1995) e Moreira (1995), de corpo ajustável às necessidades, corpo útil para o deslocamento no espaço, para a funcionalidade mecânica e, também, para a busca pela saúde e beleza. Notase que todas essas concepções se aproximam, pois o corpo precisa do movimento para ser saudável e belo. A noção de corpo saudável decorre da Educação Física Higienista do início 
do século passado no Brasil, e também, da tendência que aborda a Educação Física como promotora de Saúde. Conforme Andrieu (2004) temos aqui, 'corpos moventes' aqueles que buscam o corpo saudável e perfeito estimulados por ideologias dominantes do consumo disseminadas na mídia.

Outra percepção de corpo é a noção de conjunto, de soma das partes, apresentadas pelos E4LG, E5LG e E8LG. O E5LG disse: corpo pode ser entendido como físico, mas compõe-se também de estruturas fisiológicas, pelo mental, espiritual. Estes estudantes concebem o corpo e também a mente, como estruturas que se adicionam, o que faz recordar a res cogitans e a res extensa dos pressupostos cartesiano. Quando se trata da concepção de homem, não basta integrar como na noção de conjunto matemático e sim, interagir na dimensão das conexões e relações.

Observa-se que apenas um dos estudantes da Licenciatura Generalista, o E6LG, indicou em seu discurso uma concepção conectada à expressão, modo de exprimir atitudes e posturas por meio dos gestos. Avança em alguns aspectos, mas não alcança a concepção de humano na perspectiva de unidade e de complexidade. Ele afirma que: Corpo. É, uma representação... Toda vez que eu penso em corpo, eu penso em expressão [...] uma representação de um corpo pensante, de um corpo ativo socialmente, um corpo que fala tanto com expressão, tanto com palavras, e gestos [...]. Nota-se ele remete o corpo à uma representação do pensamento, mas um corpo que expressa, pensa e é ativo. A expressão corporal, de certo modo, ofereceu 0 direito ao sujeito de se expressar, criar, comunicar-se com o mundo e livrou o ser da estreita imitação vivida pela Educação Física tradicional. Na mesma categoria temos um estudante da Licenciatura Atual, o E4LA, que também percebe o corpo como expressão. Em seu discurso, parece-nos que houve uma mudança de importância, ou seja, um deslocamento de um corpo físico para um corpo psicológico/mental, embora seu discurso seja confuso.

Os estudantes que entendem o corpo como base para viver apresentam diferenças em seus discursos. Os discursos do E7LG e do E9LG remetem a um corpo físico, de sustentação, ou de instrumento que nos fornece a vida. O discurso do E5LA percebe o corpo relacionado à existência do ser humano como veículo neste mundo. Assim, podemos inferir que há uma aproximação com a noção de corpo concebida por Merleau-Ponty (1994).

Os discursos dos sujeitos E1LA, E2LA, E3LA, E5LA e E6LA se aproximam da noção de corpo uno e vão ao encontro do argumento de MerleauPonty (1994) em que defende que somos um corpo e que a compreensão do ser humano ocorre pela existência e percepção do mundo que se vive, destacando o corpo na unidade e na totalidade.

E1LA: - Sou eu. Meu agir, meu pensar, meu... Minha intenção, não ter intenção, eu não posso classificar ele só em estrutura física. Ah! Como meu meio de transporte. Acho que sou eu, o meu pensar, o meu agir, isso é o meu corpo, meu expressar.

Ao analisarmos o segundo tema confirmou-se o que já havia sido percebido nas entrevistaspiloto, a confusão existente entre as denominações corporeidade e corpo, o que corrobora o pensamento de Santin (2008), em que 0 sentido de corporeidade pode ser confundido com o sentido de corpo. A concepção de corpo não se separa da corporeidade. A corporeidade é o estado ou qualidade de ser corpóreo, de ser material, seria toda e qualquer organização de ordem material e de ordem cultural. Todavia, corporeidade é o que constitui um corpo, realidade existencial e humana (SANTIN, 2008, p. 103).

Da temática em questão, dos 15 estudantes entrevistados, 07 disseram que não sabiam responder. E3LG disse: - Não faço ideia do que seja. [...] Nunca ouvi falar. O E8LG falou: - Eu não vou saber explicar [...]. Entretanto, entre eles: E1LG, E6LG, E8LG disseram ter lido ou ouvido sobre o assunto, mas não estudaram de modo rigoroso, o que lhes permitiu que fizessem a interpretação do sentido de corporeidade a partir do senso comum. Este fato ocorreu também com os estudantes que não ouviram falar ou não estudaram sobre corporeidade durante a formação inicial. São eles E4LG e o E9LG. 
Quadro 2. A concepção de corporeidade.

\begin{tabular}{|l|c|}
\hline \multicolumn{1}{|c|}{ Categorias } & Estudantes \\
\hline - Não sabe responder, não sabe como explicar & E1LG, E3LG, E6LG, E7LG, E8LG, E9LG, E4LA \\
\hline - Já ouviu falar, leu sobre corporeidade & E1LG, E6LG, E8LG \\
\hline - Não/nunca ouviu falar ou estudou & E3LG, E4LG, E9LG \\
\hline - Expressão corporal & E1LG \\
\hline - Percepção do que se pode fazer com o corpo & E2LG \\
\hline - Algo relacionado à saúde (manutenção; & E4LG \\
\hline tratamento do corpo) & E4LG, E7LG \\
\hline - Algo relacionado a estética; beleza & E5LG, E7LG \\
\hline - O trabalho com o corpo & E8LG \\
\hline - O movimento em si, o movimentar-se & E9LG \\
\hline - Manifestação do que o corpo faz (corpo físico) & E1LA, E5LA, E6LA \\
\hline $\begin{array}{l}\text { - Conjunto de ações que o homem expressa, } \\
\text { realiza e vive }\end{array}$ & E2LA \\
\hline - Existência do ser humano & E3LA \\
\hline - Estudo da situação de corpo e de sujeito & \\
\hline
\end{tabular}

Os estudantes da Licenciatura Generalista, nomeadamente, E1LG, E2LG, E4LG, E5LG, E7LG, E8LG e E9LG, apresentaram uma concepção de corporeidade dualista e/ou instrumental, o que também revelou quando eles falam de suas percepções de corpo. $O$ discurso desvela apenas o que se pode fazer com o corpo no sentido biológico, como algo relacionado à saúde, à estética e ao trabalho útil. $\mathrm{O}$ movimentar-se não está relacionado ao sentido de transcendência e da evolução do ser práxico, aquele que sabe o que quer e aonde quer ir, mas sim ao de uma manifestação de um humano que usa o corpo num sentido utilitário, ou seja, corpo ajustável ao que se precisa, descrito por Assman (1995), e o corpo útil e disciplinado de Moreira (1995).

E4LG: - Corporeidade... [...] alguma coisa assim talvez seja... seja estética [...]

E5LG: - [...] pelo sentido, pela palavra, acredito que seja o trabalho com o corpo. Algo no sentido de trabalhar com o corpo.

O E1LG não conseguiu explicar claramente, assumiu não saber, mas que já ouviu falar, porém revela o seu entendimento enquanto expressão corporal, já ratificada em outras falas.

Entre os estudantes da Licenciatura Atual, 05 de 06 entrevistados compreendem a noção de corporeidade conectada à existência humana, relacionam corpo/corporeidade com movimentos intencionais e conscientes. O E2LA expressou: É a forma de existência do ser humano por meio do seu corpo. O E3LA disse: - Corporeidade [...] é o estudo dessa situação de corpo, de sujeito [...] o que faz você ser corpo, o que diferencia você a ser corpo de um objeto, o que diferencia você ser humano de uma máquina [...].

As categorias reveladas a partir das falas dos estudantes traduzidas na existência humana $e$ nos atos que este humano expressa e vive, e ainda, a preocupação com os estudos do corpo vinculados à noção de sujeito para além de objeto e de máquina, podem indicar uma superação no modo de compreender o ser humano, conforme podemos observar nas obras de Merleau-Ponty (1994) e de Sérgio (1996). 
Quadro 3. Corpo/corporeidade e a Educação Física.

\begin{tabular}{|l|c|}
\hline \multicolumn{1}{|c|}{ Categorias } & Estudantes \\
\hline - Não sabe responder & E3LG, E8LG \\
\hline $\begin{array}{l}\text { - Movimento que o corpo faz no } \\
\text { desenvolvimento motor }\end{array}$ & E1LG, E4LG \\
\hline $\begin{array}{l}\text { - Corpo relacionado com a saúde, bem-estar e } \\
\text { qualidade de vida }\end{array}$ & E2LG, E4LG, E5LG, E7LG, E9LG \\
\hline - Corpo relacionado com a estética, beleza & E4LG, E5LG, E7LG \\
\hline - Corpo vinculado a mídia & E2LG, E4LG, E5LG \\
\hline $\begin{array}{l}\text { - Corpo uno, integral, total, movimento } \\
\text { intencional, formação integral }\end{array}$ & E6LG, E1LA, E2LA, E3LA, E4LA, E5LA, E6LA \\
\hline
\end{tabular}

Ao perguntar com que corpo/corporeidade a atual Educação Física está preocupada, verificouse que 08 estudantes da amostra total de 15, sendo 03 da Licenciatura Generalista e 05 da Licenciatura Atual, questionaram se 0 pesquisador estava se referindo à Educação Física escolar (Licenciatura) ou não escolar (Bacharel/Esporte), ou ainda, se era sobre 0 curso que freqüentavam, ou se era a área de uma forma geral. Foi esclarecido aos entrevistados que a pergunta era sobre a Educação Física de um modo geral, mas que eles poderiam responder de modo específico, caso entendessem haver necessidade. Infere-se que este fato ocorreu porque a Universidade Estadual de Londrina oferece 03 (três) Cursos de Graduação: (Educação Física Licenciatura, Educação Física Bacharel e Esporte). França (2009) explica que a Educação Física apresenta diversas tendências atualmente, das quais, dependendo da área de atuação e das emergências paradigmáticas, observam-se diferentes concepções de corpo vinculadas a elas.

Embora haja vasta literatura apontando novas tendências no âmbito da Educação Física a fim de romper com o paradigma dualista cartesiano, verificou-se, por meio das categorias levantadas, que a maioria dos estudantes da Licenciatura Generalista, sendo eles: E1LG, E2LG, E4LG, E5LG, E7LG e E9LG, revelaram, em seus discursos, aproximações com a concepção de corpo relacionada ao desenvolvimento motor; corpo físico; corpo ligado à saúde ou à estética com influência da mídia. Infere-se que, na percepção dos estudantes, a Educação Física Generalista se ocupou do corpo físico tão só, e o estudou fragmentado, decorrente da separação abissal cartesiano-newtoniana, concepção esta sob qual nasceu e se fundamentou a Educação Física. E, também, não superou a noção de corpo ligada à instrumentalidade de um mercado corpóreo vigente.

Dois estudantes, o E3LG e o E8LG, disseram não saber responder com que corpo/corporeidade a Educação Física está preocupada. O E3LG disse: - Nossa! Eu não sei te responder.

Entretanto, o E6LG apresentou uma noção de "corpo pensante". Ele entende que: - A Educação Física está preocupada com [...] um corpo pensante, um corpo que realiza o movimento e sabe o porquê de estar realizando o movimento [...]. Infere-se a intenção em colocar o corpo na condição de sujeito, mesmo que para isso empreste os elementos da filosofia cartesiana, no caso o sujeito. Porém, revelou um entendimento de corpo numa perspectiva mais avançada em relação aos demais de seu curso.

Os discursos dos estudantes E1LA, E2LA, E3LA, E4LA, E5LA e E6LA demonstram que a concepção de corpo, assimilada durante o curso de Licenciatura em Educação Física, é a de corpo que não se separa da mente. Conclui-se que a concepção apropriada está para além de um humano que tem um físico tão só, e também, na percepção do ser inteiro, uno, da conexão entre o sensível e o inteligível. O E1LA explicou que o curso se ocupa [...] com esse corpo uno, integral sem separar na maneira cartesiana [...]. E ainda, - E6LA disse: [...] no nosso currículo considera a totalidade do homem, o homem enquanto ser completo [...]. 
Observa-se na atualidade, no âmbito da Educação Física, a defesa do corpo na perspectiva da unidade nas propostas de Soares e colaboradores, de Elenor Kunz, de Jocimar Daólio, de Mauro Betti e de Reiner Hildebrandt relatados por Campanholi (2008) e legítimo em Manuel Sérgio (1996), pois se verifica nas proposições do último autor uma motricidade intencional compreendida como uma manifestação viva e complexa da corporeidade, concebendo o ser humano na unidade e complexidade.

\section{À guisa de conclusão}

Esta pesquisa revelou que, na Universidade Estadual de Londrina, a formação inicial em Educação Física, a partir do Currículo Generalista, favoreceu a construção da concepção de corpo pautado no paradigma racionalismo antropológico cartesiano, concepção esta muito presente na história da Educação Física. E que a formação Inicial, a partir do Currículo Atual, formação específica de professores, empenhou-se na construção de uma concepção de corpo/corporeidade, superando esse paradigma citado, ou seja, desencadeou um processo de apropriação de uma concepção de ser humano centrado na unidade e na totalidade, entre o sensível e o inteligível.

Analisaram-se os discursos de 15 estudantes que participaram da pesquisa, via entrevista semiestruturada, sendo 09 da Licenciatura Generalista e 06 da Licenciatura Atual.

Numa perspectiva macro, verificou-se que no currículo Licenciatura Generalista: 04 estudantes aproximaram-se mais de uma concepção de corpo dualista, corpo máquina, marcado pela fragmentação abissal e pela divisão entre 0 corporal e o mental; 04 estudantes desvelaram uma concepção de corpo dualista instrumental, útil e ajustável ao que se precisa e susceptível a incorporar ideais sociais dominantes. Apenas 01 estudante percebeu que 0 humano não é somente uma substância física, sob o argumento de um corpo que expressa, sente e pensa.

No currículo Licenciatura Atual, 05 estudantes se aproximaram da concepção de humano, que compreende o corpo na unidade com a mente, na conexão do sensível com o inteligível, ou seja, na totalidade e na globalidade, cujo entendimento, segundo os próprios estudantes, fora construído ao longo da formação inicial profissional; 01 estudante, apesar de demonstrar um avanço em busca da superação da fragmentação do humano, não desvelou a concepção de unidade claramente definida, portanto infere-se que está numa fase de transição ou não compreendeu as discussões durante a sua formação.

Verificou-se que existem diferenças de concepção de corpo/corporeidade nos diferentes currículos. Infere-se a partir dos estudos realizados que essa diferença entre os dois cursos ocorreu tendo em vista a distinção entre os objetivos da formação profissional, o perfil do concluinte e também os princípios que fundamentam os cursos. Leva-se ainda em consideração que os docentes dos dois cursos são os mesmos e não houve modificação e nem inclusão de novos conceitos de corpo/corporeidade nas disciplinas.

Observou-se que os saberes e os fazeres disseminados no âmbito dos diferentes cursos de graduação influenciaram a construção da concepção de corpo/corporeidade dos estudantes. Todavia, fazem-se necessárias, ainda, investigações futuras, tais como: qual a concepção de corpo/corporeidade presente nos conteúdos sugeridos no Currículo Atual e, também, dos docentes que atuam na formação inicial, pois por meio destas teríamos uma análise mais abrangente.

A comunidade científica da Educação Física tem se empenhado em promover o salto qualitativo na área da produção teórica $e$ filosófica. E um dos aspectos é a consolidação de uma concepção de corpo humano que não esteja pautado nos fragmentos e na divisão. Infere-se, portanto, que para alcançar a qualidade e efetuar uma ruptura com o passado dualista, mentecorpo, precisa-se partir em defesa da unidade e da complexidade ontológica.

Deve-se provocar, no âmbito da formação inicial, a compreensão do humano enquanto corpo-alma, sensível-inteligível, ou seja, enquanto unidade e totalidade. Faz-se necessário suscitar a concepção de homem, traduzida na corporeidade viva e no movimento intencional, carregado de sentido e de significado, porque perspectiva um ressignificar da ação, no âmbito da Educação Física, independente da atuação profissional.

A formação em licenciatura em Educação Física, compromissada com a construção de uma concepção de humano na unidade e na totalidade 
do ser, poderá contribuir com a formação e a educação das crianças e dos jovens no âmbito das aulas de Educação Física. Entretanto, não se pode afirmar que essa concepção se refletirá diretamente na ação docente, no âmbito da escola, pois a concepção de corpo é apenas um dos vetores da formação do futuro profissional.

Há que se ter atenção à complexidade e à totalidade humana, atenção a uma nova concepção de racionalidade, que é diferente de racionalismo, o qual envolve o pensar, o sentir e o agir. Temos responsabilidades na formação de professores, portanto convidamos todos a conceberem o humano inteiro, sem distinção, sem separação.

\section{Referências}

ANDRIEU, B. A nova filosofia do corpo. Lisboa: Instituto Piaget, 2004.

ANJOS, J. L. Corporeidade, higienismo e linguagem. Vitória: UFES, 1995.

ASSMANN, H. Paradigmas educacionais e corporeidade. 3. ed. Piracicaba: Unimep, 1995.

CAMPANHOLI, C. A. O. A unidualidade humana para o ensino da Educação Física: uma proposta de concepção não linear de corpo sob o paradigma da complexidade. 2008, $131 \mathrm{f}$.

Dissertação (Mestrado em Educação) - Centro de Educação, Comunicação e Artes, Programa de Pós-Graduação em Educação, Universidade Estadual de Londrina, Londrina, 2008.

FILETTI, E.; SILVA, R.. Corpo e Linguagem: perspectivas discursivas e interdisciplinares.

Revista Solta a Voz, Goiânia, v. 19, n. 2, p.17597, 2008. Disponível em: $<$ http://revistas.ufg.br/index.php/sv/article/view/590 7 >. Acesso em: 20 dez. 2009.

FRAGA, A. F. Anatomias emergentes e o bug muscular: pedagogias do corpo no limiar do século XXI. In: SOARES, C. L. (org.). Corpo e história. Campinas: Autores Associados, 2001. Cap. 4, p. 61-77.

FRANÇA, R. M. Crises e emergências paradigmáticas na ciência, no currículo e na educação física: repercussões sobre a formação de professores. 2009, 171f. Dissertação de (Mestrado em Educação) - Centro de Educação, Comunicação e Artes, Programa de Pós-

Graduação em Educação. Universidade Estadual de Londrina, Londrina, 2009.

GALLO, S. Corpo ativo e a filosofia. In: MOREIRA, W. W. (org.) Século XXI: a era do corpo ativo. Campinas, SP: Papirus, 2006. Cap. 1, p. 9-30.

GONÇALVES, M. A. S. Sentir, pensar, agir: corporeidade e educação. Campinas: Papirus, 1994.

GUSDORF, G. Mito e metafísica. São Paulo: Convívio, 1980.

GUIRALDELLI JUNIOR, P. O corpo: filosofia e educação. São Paulo, SP: Ática, 2007.

INFORSATO, E. C. A Educação entre o controle e a libertação do corpo. In: MOREIRA, W. W. (org.) Século XXI: a era do corpo ativo. Campinas, SP: Papirus, 2006. Cap. 5, p. 91-108.

JANA, J. E. A. Para uma teoria do corpo humano: apresentação e crítica da teoria do corpo humano de Pedro Laín Entralgo. Lisboa: Instituto Piaget, 1995.

JOHNSON, D. Corpo. Rio de Janeiro: Nova Fronteira, 1990.

LAKATOS, E. M.; MARCONI, M. A. Técnicas de pesquisa: planejamento e execução de pesquisas, amostragens e técnicas de pesquisas, elaboração, análise e interpretação de dados. 5 . ed. São Paulo: 2002.

MARTINS, J. A pesquisa qualitativa. In: FAZENDA, I. (org.). Metodologia da pesquisa educacional. São Paulo: Cortez, 1989.

MASINI, E. F. S. Enfoque fenomenológico de pesquisa em educação. In: FAZENDA, I. (org.). Metodologia da pesquisa educacional. São Paulo: Cortez, 1989. Cap. 4, p. 47-58.

MERLEAU-PONTY, M. Fenomenologia da percepção. São Paulo: M. Fontes, 1994.

MOREIRA, W. W. Corpo presente num olhar panorâmico. In: MOREIRA, W. W. (org.). Corpo pressente. Campinas: Papirus, 1995. Cap. 1, p. 17-36.

PLATÃO. Vida e obra. 2. ed. São Paulo: Abril Cultural, 1979.

PEREIRA, A. M. Motricidade Humana: a complexidade e a práxis educativa. 2006, $382 f$. Tese (Doutoramento em Ciências da Motricidade Humana) - Universidade da Beira Interior, Covilhã-Portugal.

RICOEUR, P. O conflito das interpretações: ensaios de hermenêutica. Rio de Janeiro: Editorial Imago, 1978. 
SANT'ANNA, D. B. É possível realizar uma história do corpo? In: SOARES, C. L. (org.).

Corpo e história. Campinas: Autores associados, 2001. Cap. 1, p. 3-23.

SANTIN, S. O corpo simplesmente corpo.

Revista Movimento, Porto Alegre, v. 7, n. 15, p. 57-74, 2001. Disponível em:

$<$ http://seer.ufrgs.br/Movimento/article/view/2623/ 1252>. Acesso em: 18 jan. 2010.

SANTIN, S. Corporeidade. In: GONZÁLEZ, F. J.; FENSTERSEIFER, P. E. (org.). Dicionário crítico de Educação Física. 2 ed. ljuí: Unijuí, 2008. p. 103-4.

SERGIO, M. Epistemologia da motricidade humana. Cruz Quebrada - Lisboa: Edições Faculdade de Motricidade Humana, 1996.

SERGIO, M. Uma reflexão sobre o corpo. In: RODRIGUES, D. (org.). 0 corpo que (des)conhecemos. Lisboa: Faculdade de Motricidade Humana, 2005. p. 205-16.

SILVA, P. C. O lugar do corpo: elementos para uma cartografia fractal. Lisboa: Instituto Piaget 1999.

TAVARES, G. A temperatura do corpo. Lisboa: Instituto Piaget, 2001.

Agradecimentos: agradecemos ao $\mathrm{CNPq}$ pelo apoio e financiamento desta pesquisa.

\section{Endereço:}

Ana Maria Pereira

UEL - Depto. de Estudos do Movimento Humano

Campus Universitário

Rodovia Celso Garcia Cid, PR 445, Km 380

Caixa Postal 6001

Londrina PR Brasil

86051-980

Telefones: (43) 9903-1683 / (43) 3024-5625

e-mail: apereira@uel.br

Recebido em: 14 de fevereiro de 2012.

Aceito em: 18 de novembro de 2012.

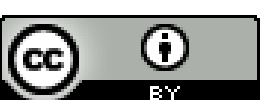

Motriz. Revista de Educação Física. UNESP, Rio Claro, SP, Brasil - elSSN: 1980-6574 - está licenciada sob Creative Commons - Atribuicão 3.0 